\title{
Updated Inventory of Amphibians, Reptiles and Mammals of the Bukit Timah Nature Reserve, Singapore
}

\author{
R.C.H. Teo \& N.J. Thomas \\ Conservation, National Parks Board, \\ 1 Cluny Road, 259569 Singapore \\ Robert_TEO@nparks.gov.sg
}

\begin{abstract}
A two-year survey at Bukit Timah Nature Reserve, Singapore, found a high diversity of amphibian, reptile and mammal species. A total of 81 indigenous species was recorded -18 amphibians, 40 reptiles and 23 mammals. The updated inventory comprises 115 species -21 amphibians, 60 reptiles and 34 mammals ever historically recorded within the reserve.
\end{abstract}

Keywords. Community structure, species assemblage, tropical rain forest, vertebrate survey

\section{Introduction}

A survey of amphibians, reptiles and mammals was carried out from May 2015 to September 2016 (the Survey), as part of a comprehensive biodiversity survey of the Bukit Timah Nature Reserve (BTNR) initiated by the National Parks Board (NParks) (see Chan \& Davison, 2019). The purpose of the Survey was to update the baseline inventory established by Teo \& Rajathurai (1997).

\section{Methods}

\section{Transect Surveys}

As most amphibians, reptiles and mammals are nocturnal, overnight transect surveys were an important component of the Survey. Each overnight survey stretched from $1700 \mathrm{hrs}$ to $0900 \mathrm{hrs}$ the next day. Throughout the period, each team of three to seven surveyors was assigned time slots of $2-4$ hours to walk transects of up to $3 \mathrm{~km}$ each. A total of 11 overnight surveys were carried out.

The overnight surveys were complemented by separate day transect surveys, during which the transects were covered 54 times in the morning to sample diurnal species.

\section{Bat Surveys}

Mist nets of $6 \mathrm{~m}$ and $12 \mathrm{~m}$ lengths, and mesh thickness of 30 denier, were used to survey bats. These were set to cover a trapping area from the forest floor to a height of about $2.5 \mathrm{~m}$. Where site conditions permit, a three-tier $6 \mathrm{~m}$ net system was also used, reaching a height of about $10 \mathrm{~m}$. Two-bank harp traps were also deployed across 
known or suspected flyways of microchiropteran bats. The nets and harp traps were deployed from before dusk until about $2100 \mathrm{~h}$ on six nights.

In addition, passive and active ultrasonic bioacoustic recorders were used to survey microchiropteran bats through their echolocation calls. Two Song Meter SM3+ and two Echo Meter EM3+ recorders were used.

\section{Small Mammal Trapping}

Tomahawk ${ }^{\circledR}$ wire-mesh traps and Sherman ${ }^{\circledR}$ aluminium box traps were utilised for small mammals like treeshrews, rats and squirrels. Between May 2016 and May 2017, 50 sequentially numbered traps (25 Tomahawk ${ }^{\circledR}$ traps, followed by 25 Sherman ${ }^{\circledR}$ traps) were deployed along a pre-selected transect, at $20 \mathrm{~m}$ intervals, a day prior to each survey. Odd-numbered traps were baited with banana while even-numbered traps were baited with papaya. Captured animals were identifed before release.

\section{Camera Trapping}

A total of 20 to 25 camera traps (20 Cuddleback ${ }^{\circledR}$ and 5 Bestguarder $®$ ) were deployed from November 2015 to May 2016. Each camera was checked on a monthly basis, when SD cards and batteries were also replaced.

\section{Ad-hoc Sightings}

Incidental sightings recorded during the Survey period, apart from the above survey methods, were also considered in the update of the checklist.

\section{Results}

The Survey recorded 81 species indigenous to Singapore, consisting of 18 amphibian, 41 reptile and 23 mammal species. Together with reported biodiversity records from August 1997 to 31 July 2017, the Survey allowed the BTNR checklist established by Teo \& Rajathurai (1997) to be updated to 115 species - 21 amphibians, 60 reptiles and 34 mammals (Appendix 1). There were 18 additions to the checklist - one amphibian, eight reptile and nine mammal species. A selection of the species encountered, and the survey teams at work, are shown in Fig. 1 and 2.

\section{Amphibians}

A total of 18 native amphibian species were recorded. The single addition to the checklist of amphibians for BTNR was Microhyla butleri $(\mathrm{n}=4)$. The most commonly recorded amphibians were Chalcorana labialis $(\mathrm{n}>130)$, Leptobrachium nigrops $(\mathrm{n}>120)$ and Kalophrynus limbooliati $(\mathrm{n}=118)$.

A total of 16 amphibian species were recorded along transects during overnight surveys - commonly encountered species included Chalcorana labialis, Kalophrynus limbooliati and Leptobrachium nigrops. Eight amphibian species were recorded along transects during daytime surveys - Kalophrynus limbooliati was often detected by its call. 

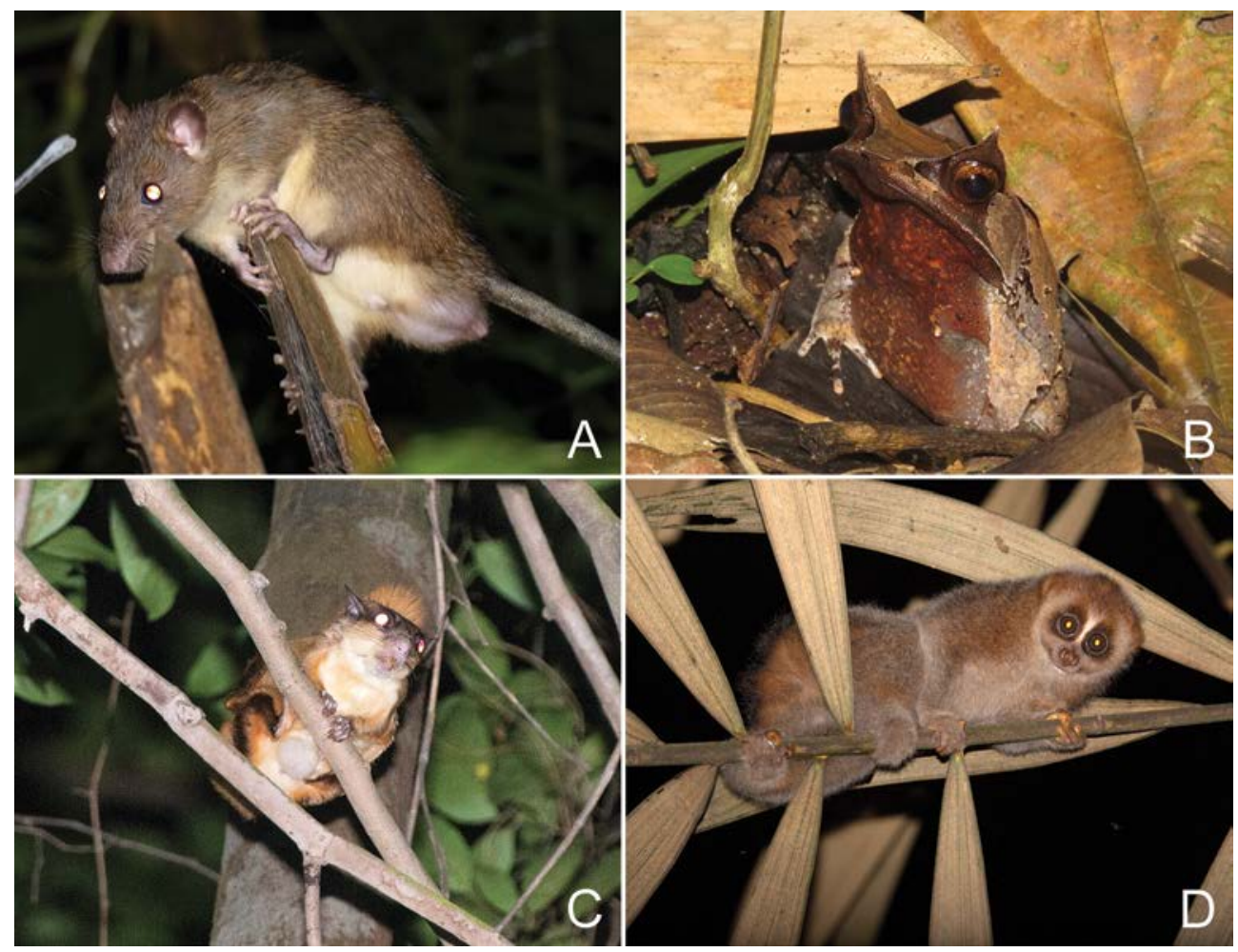

Fig. 1. A. Rattus annandalei, the dominant nocturnal small mammal of the forest floor. B. Cryptic colouring of Megophrys nasuta makes it hard to spot amongst leaf litter. C. Iomys horsfieldii, although a new record for BTNR since 1997, was frequently encountered. D. Nycticebus coucang is also a new record for BTNR since 1997. (Photos: A, G. Seow; B, R. Teo; C, V. D’Rozario; D, I.S. Law)

Reptiles

A total of 40 indigenous reptile species were recorded. There was also one non-indigenous species, Calotes versicolor. The Survey produced eight additions to the checklist of reptiles for BTNR, including Cyrtodactylus majulah $(\mathrm{n}=1)$, Dendrelaphis cyanochloris $(\mathrm{n}=1)$, Dendrelaphis kopsteini $(\mathrm{n}=2), \quad$ Draco quinquefasciatus $(\mathrm{n}=3)$, Hemiphyllodactylus typus $(\mathrm{n}=3)$ and Ptyas fusca $(\mathrm{n}=2)$. Ahaetulla mycterizans $(\mathrm{n}=20)$ and Dasia grisea $(\mathrm{n}=2)$ were not recorded by Teo \& Rajathurai (1997) but were found in BTNR before and during the Survey.

The most commonly recorded reptiles were Cnemaspis peninsularis $(\mathrm{n}=97)$, Varanus nebulosus $(\mathrm{n}=61)$, Gekko monarchus $(\mathrm{n}=55)$, Eutropis multifasciatus $(\mathrm{n}=50)$, Ahaetulla mycterizans $(\mathrm{n}=24)$ and Tropidolaemus wagleri $(\mathrm{n}=22)$.

A total of 25 reptile species were recorded along transects during overnight surveys, when Cnemaspis peninsularis and Gekko monarchus were the species most frequently encountered. Day transects recorded 19 reptile species and Eutropis multifasciatus and Varanus nebulosus were the most commonly seen. 

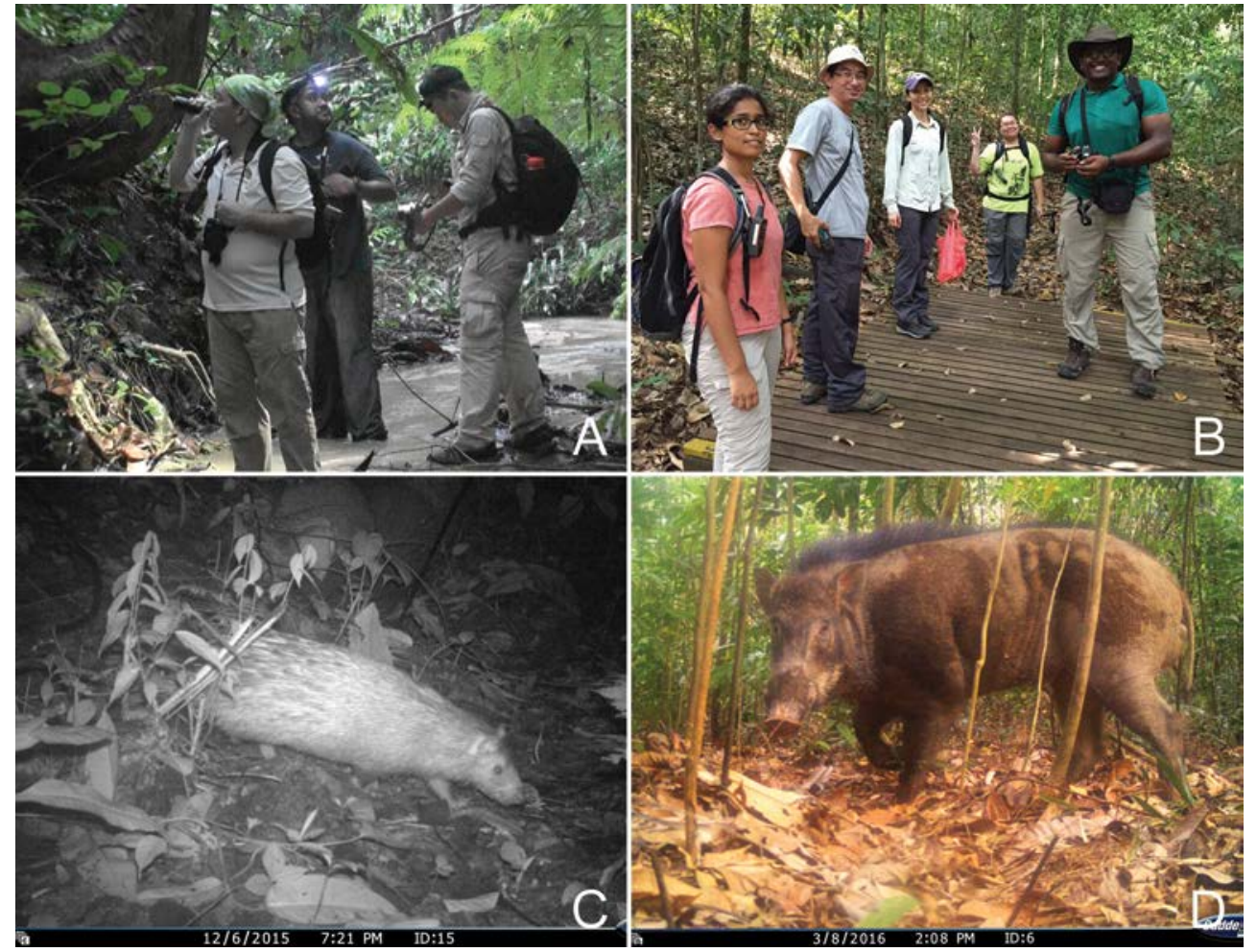

Fig. 2. A. Vertebrate surveys included transects along streams. B. Volunteers helped to set out bait and small mammal traps. C. Hystrix brachyura was detected by camera trapping. D. Sus scrofa has become abundant and widespread within the past decade. (Photos: A, R. Teo; B, V. D’Rozario; C \& D, NParks).

The terrapin Heosemys spinosa was trapped on two occasions in traps deployed for small mammals.

Camera traps recorded two diurnal species, Eutropis multifasciatus and Varanus nebulosus.

\section{Mammals}

A total of 23 native mammal species were recorded. There were nine additions to the checklist of mammals for BTNR including Eonycteris spelaea $(\mathrm{n}>100)$, Hystrix brachyura $(\mathrm{n}=28)$, Iomys horsfieldii $(\mathrm{n}=81)$, Nycticebus coucang $(\mathrm{n}=7)$, Paradoxurus musangus $(\mathrm{n}=18)$ and Sus scrofa $(\mathrm{n}=270)$ from the Survey, and Cheiromeles torquatus, Hipposideros bicolor and Pipistrellus stenopterus prior to the Survey.

The most commonly recorded mammals included Macaca fascicularis $(\mathrm{n}=691)$, Sus scrofa $(\mathrm{n}=270)$, Callosciurus notatus $(\mathrm{n}=247)$, Tupaia glis $(\mathrm{n}=229)$, Sundasciurus tenuis $(\mathrm{n}=214)$ and Cynocephalus variegatus $(\mathrm{n}=129)$.

A total of 14 mammal species were recorded along transects during overnight surveys. The commonly encountered species included Galeopterus variegatus and 
Iomys horsfieldii. Day transects recorded six mammal species and Callosciurus notatus, Macaca fascicularis, Sundasciurus tenuis and Tupaia glis were frequently encountered.

Only 29 bats were captured, in harp traps $(n=20,69 \%)$ and mist nets $(n=9$, $31 \%)$, consisting of Rhinolophus lepidus $(\mathrm{n}=28,97 \%)$ and Penthetor lucasi $(\mathrm{n}=1,3 \%)$. Bioacoustic surveys, however, frequently detected Rhinolophus lepidus (within the forest canopy) and Scotophilus kuhlii (above the forest canopy and in forest clearings).

There were 137 small mammal trappings, dominated by Tupaia glis $(\mathrm{n}=87$, $64 \%)$ and Rattus annandalei $(n=41,30 \%)$. The only other mammal species trapped was Callosciurus notatus ( $\mathrm{n}=6,4 \%)$.

Camera traps recorded 14 species, with high capture rates for Macaca fascicularis, Sus scrofa and Tupaia glis.

\section{Annotated Checklist}

The following annotated checklist provides an account of each species recorded from BTNR. Unless otherwise indicated, these species are also found in the Central Catchment Nature Reserve (CCNR). Where comparison of records to the survey carried out by Teo \& Rajathurai (1997) from 1996 to 1997 is mentioned, reference is made to Rajathurai \& Teo (1998), which was the corresponding report submitted to NParks for BTNR. This is necessary as Teo \& Rajathurai (1997) did not indicate a breakdown of records from 1987 to 1995 and from 1996 to 1997.

\section{CLASS AMPHIBIA}

\section{ORDER GYMNOPHIONA \\ Family Ichthyophiidae}

\section{Ichthyophis paucisulcus Taylor, 1960}

Vernacular Name: Yellow-banded Caecilian

This highly cryptic caecilian was not recorded during the Survey, but Lim et al. (2015) confirmed that it was still holding out in BTNR since the last records from Jungle Fall Valley in 1984 and 1989 (Teo \& Rajathurai, 1997). Two juveniles were found in a stream at the eastern part of the reserve during a freshwater biodiversity survey. 


\section{ORDER ANURA \\ Family Bufonidae}

2. Duttaphrynus melanostictus (Schneider, 1799),

(Documented as Bufo melanostictus in Teo \& Rajathurai, 1997).

Vernacular Name: Asian Toad

In contrast to the 60 recorded by Rajathurai \& Teo (1998), there were only 23 sightings, mostly along Main Road and Quarry Road, and at the peripheral areas of BTNR.

\section{Pelophryne signata (Boulenger, 1894)}

Vernacular Name: Saint Andrew’s Cross Toadlet

This species had not been recorded since its rediscovery in 1989 (Teo \& Rajathurai, 1997) until the Survey - nine were found within BTNR, and two were also heard calling from the adjacent Hindhede Quarry, a new locality for the species. One was found in a phytothelm - a water-filled treehole. Leong \& Teo (2009) provided an account of the larvae found in a tree hole. This tiny toad has a highly localised distribution within BTNR and has not been recorded anywhere else in Singapore.

\section{Family Megophryidae}

4. Leptobrachium nigrops Berry \& Hendrickson, 1963

Vernacular Name: Black-eyed Litter Frog

Excluding tadpoles, there were over 60 records in contrast to the 21 reported by Rajathurai \& Teo (1998). It is easily recognised by its distinctive "machine gun" like call.

\section{Megophrys nasuta (Schlegel, 1858)}

Vernacular Name: Malayan Horned Frog

This species is difficult to detect by sight due to its excellent camouflage against the leaf litter of the forest. Usually found in the vicinity of streams, a total of 26 were recorded, primarily by the loud, distinctive call. Rajathurai \& Teo (1998) also recorded 26. 


\section{Family Dicroglossidae}

\section{Fejervarya cancrivora (Gravenhorst, 1829)}

(Documented as Rana cancrivora in Teo \& Rajathurai, 1997)

Vernacular Name: Crab-eating Frog

More commonly associated with mangroves, where it can tolerate brackish water, this species can, however, also be found in disturbed habitats. There were only two records from BTNR, both from Lasia Stream.

\section{Fejervarya limnocharis (Gravenhorst, 1829),}

(Documented as Rana limnocharis in Teo \& Rajathurai, 1997).

Vernacular Name: Field Frog

This is another common frog of disturbed areas. Eight frogs were found at the summit of Bukit Timah and along tracks at the periphery of the reserve.

\section{Limnonectes blythii (Boulenger, 1920)}

Vernacular Name: Malayan Giant Frog

Growing to a snout-to-vent length of over $25 \mathrm{~cm}$, this is the largest indigenous anuran in Singapore. Teo \& Rajathurai (1997) reported this to be confined to BTNR and CCNR, but it has since been found in Singapore Botanic Gardens (Teo, 2003; Lim \& Chua, 2014), King Albert's Park in Holland Woods (Teo, 2003), Sungei Buloh Wetland Reserve (Chan \& Goh, 2010), Western Catchment Area (R.C.H. Teo, pers. obs., 2005-2007) and Bukit Gombak (Lim, 2013; Lim, 2014). The Survey produced 18 records within BTNR and another 21 were found in a stream running parallel to the pipeline reserve from the park connector between Zhenghua Nature Park and Dairy Farm Road. Rajathurai \& Teo (1998) recorded it 34 times.

\section{Limnonectes malesianus (Kiew, 1984)}

(Documented as Limnonectes malesiana in Teo \& Rajathurai, 1997)

Vernacular Name: Malesian Frog

There were 16 sightings of this frog and a single record in a stream running parallel to the pipeline reserve from the park connector to Zhenghua Nature Park to Dairy Farm Road. This is comparable to the 14 recorded by Rajathurai \& Teo (1998). Closely associated with streams, it has also been found in the Western Catchment Area (Baker \& Lim, 2012; R.C.H. Teo, pers. obs., 2005-2007). 
10. Limnonectes plicatellus (Stoliczka, 1873)

(Documented as Rana plicatella in Teo \& Rajathurai, 1997)

Vernacular Name: Rhinoceros Frog.

Usually found in streams, this frog is more often heard than seen. There were 22 records, a reduction from the 48 reported by Rajathurai \& Teo (1998). In addition, two were found on the Kampong Trail and one in a stream running parallel to the pipeline reserve from the park connector between Zhenghua Nature Park and Dairy Farm Road.

11. Occidozyga sumatranus (Peters, 1877)

(Documented as Occidozyga laevis in Teo \& Rajathurai, 1997)

Vernacular Name: Yellow-bellied Puddle Frog

There were five records of this tiny frog, comparable to the two noted by Rajathurai \& Teo (1998). This species has also been recorded on Pulau Tekong (Lim et al., 2016; R.C.H. Teo, pers. obs., 2001-2002) and in the Western Catchment Area (R.C.H. Teo, pers. obs., 2005-2007).

\section{Family Ranidae}

\section{Chalcorana labialis (Boulenger, 1887)}

(Documented as Rana chalconota in Teo \& Rajathurai, 1997)

Vernacular Name: Copper-cheeked Frog

In contrast to the 54 documented by Rajathurai \& Teo (1998), the Survey produced 130 records. It was also recorded in Dairy Farm Nature Park and a stream running parallel to the pipeline reserve from the park connector between Zhenghua Nature Park and Dairy Farm Road. This frog has also been found on Pulau Tekong (Lim et al., 2016; R.C.H. Teo, pers. obs., 2001-2002) and in the Western Catchment Area (R.C.H. Teo, pers. obs., 2005-2007).

13. Hylarana erythraea (Schlegel, 1837)

(Documented as Rana erythraea in Teo \& Rajathurai, 1997)

Vernacular Name: Green Paddy Frog

This species is typically found in ponds and lakes in open habitats. There were only three records, all at Catchment Pond, comparable to the four reported by Rajathurai \& Teo (1998). 
14. Pulchrana laterimaculata (Barbour \& Noble, 1916)

(Documented as Rana baramica in Teo \& Rajathurai, 1997)

Vernacular Name: Masked Rough-sided Frog

Usually detected by its calls, there were 19 records, in contrast to only three by Rajathurai \& Teo (1998). A single frog was also heard calling in Dairy Farm Nature Park. Usually found in the mature forest, it was, however, recorded by Siow et al. (2014) "along abandoned railway track flanked by secondary forest and scrub" at Holland Woods.

\section{Family Rhacophoridae}

15. Nyctixalus pictus (Peters, 1871)

Vernacular Name: Cinnamon Bush Frog

This dimunitive frog was recorded 33 times, a decrease from the 67 by Rajathurai \& Teo (1998). There was also a record in Dairy Farm Nature Park. Recorded primarily by its distinctive vocalisations, it was sometimes found some distance away from stream habitats.

16. Polypedates leucomystax (Gravenhorst, 1829)

Vernacular Name: Four-lined Tree Frog

A common species in Singapore, this was recorded 16 times, while 32 were documented by Rajathurai \& Teo (1998).

\section{Theloderma horridum (Boulenger, 1903)}

Vernacular Name: Thorny Bush Frog

Hard to detect due to its highly cryptic camouflage, this tiny frog was not found during the Survey, but was recorded in 2009 from BTNR (Figueroa \& Selveindran, 2011). Previously known only from six records in BTNR (Teo \& Rajathurai, 1997), Figueroa \& Selveindran (2011) also recorded it from Nee Soon Freshwater Swamp Forest.

\section{Family Microhylidae}

18. Kalophrynus limbooliati (Matsui, Nishikawa, Belabut, Norhayati \& Yong, 2012) (Documented as Kalophrynus pleurostigma in Teo \& Rajathurai, 1997)

Vernacular Name: Lim's Black-spotted Sticky Frog 
This was the most commonly recorded anuran with over 135 records in contrast to the 69 by Teo \& Rajathurai (1997). There were also many records between Dairy Farm Nature Park and Zhenghua Nature Park. Observations confirm the note by Teo \& Rajathurai (1997) that this is a leaf-litter species, not dependant on streams. Although most records were from dusk to dawn, calls were also heard in the morning up to 1252 hours.

19. Kaloula pulchra (Gray, 1983)

Vernacular Name: Banded Bullfrog

This introduced species has established itself across Singapore in open habitats. It was found to have penetrated the forest in BTNR by Teo \& Rajathurai (1997), but none was recorded in the Survey. A single frog was sighted in Dairy Farm Nature Park.

20. Microhyla butleri Boulenger, 1900

Vernacular Name: Painted Chorus Frog

Usually found in disturbed habitats, this frog was not documented in BTNR by Teo \& Rajathurai (1997), but four were recorded near streams at the periphery of the reserve. This is the only addition to the anuran biodiversity of BTNR.

\section{Microhyla heymonsi Vogt, 1911}

Vernacular Name: Dark-sided Chorus Frog

This is another common species in Singapore, usually associated with disturbed habitats. Rajathurai \& Teo (1998) had 15 records from the periphery of BTNR near Taban Valley. This has penetrated the forest proper and there were over 10 records.

\section{CLASS REPTILIA}

\section{ORDER TESTUDINES}

Family Geoemydidae

1. Heosemys spinosa Gray, 1830

Vernacular Name: Spiny Hill Terrapin

Two adult males were captured in Tomahawk ${ }^{\circledR}$ traps laid out for small mammals. This compares with the six reported by Rajathurai \& Teo (1998). 
2. Trachemys scripta elegans (Wied, 1839)

Vernacular Name: Red-eared Slider

Commonly found in ponds, lakes and waterways in Singapore where it has been released, this feral species was not detected. Rajathurai \& Teo (1998) recorded one at Catchment Pond. It is abundant in Hindhede Quarry immediately adjacent to BTNR.

\section{ORDER SQUAMATA \\ Family Agamidae}

\section{Aphaniotis fusca (Peters, 1864)}

Vernacular Name: Earless Agamid

There were two records of this forest species in comparison to the four by Rajathurai \& Teo (1998).

\section{Bronchocela cristatella (Kuhl, 1820) \\ Vernacular Name: Green Crested Lizard}

Once common across Singapore, this agamid is now more often found in wooded areas and forest, possibly due to competition with Calotes versicolor, an alien invasive species. There were seven sightings compared to three reported by Rajathurai \& Teo (1998).

\section{Calotes versicolor (Daudin, 1802)}

Vernacular Name: Changeable Lizard

This feral species is now entrenched in Singapore, and can be found in roadside greenery, parks, gardens and open areas. Although Rajathurai \& Teo (1998) documented five sightings, only two were recorded in the Survey, at the periphery of the reserve.

\section{Draco melanopogon Boulenger, 1887}

Vernacular Name: Black-bearded Flying Dragon

A forest species, this was recorded 16 times, an increase from the six reported by Rajathurai \& Teo (1998). There was also a record in Dairy Farm Nature Park. Chia \& Soh (2014) also recorded it on the Kampung Trail, near BTNR. 
7. Draco quinquefasciatus Hardwicke \& Gray, 1827

Vernacular Name: Five-banded Flying Dragon

First recorded from Singapore in 2001 in CCNR (Baker \& Lim, 2012), there were four sightings at the eastern part of the reserve. This is an addition to BTNR's checklist.

8. Draco sumatranus Schlegel, 1844

(Documented as Draco volans in Teo \& Rajathurai, 1997)

Vernacular Name: Sumatran Flying Dragon

This species is usually found on trees in open habitats, including parks and gardens. There was only a single record at the periphery of BTNR, and two in Dairy Farm Nature Park. Rajathurai \& Teo (1998) recorded two sightings.

\section{Family Gekkonidae}

9. Cnemaspis peninsularis Grismer, Wood, Anuar, Riyanto, Ahmad, Muin, Sumontha, Grismer, Onn, Quah \& Pauwels, 2014

(Documented as Cnemaspis kendalli in Teo \& Rajathurai, 1997)

Vernacular Name: Peninsular Rock Gecko

There were 98 records in contrast to 46 by Rajathurai \& Teo (1998). One was also observed by a stream running parallel to the pipeline reserve from the park connector between Zhenghua Nature Park and Dairy Farm Road. It has also been recorded on Venus Drive (Ng, 2014) and Pulau Tekong (Lim et al., 2016). Active both in the day and night, it is usually found on rocks and tree trunks.

10. Cyrtodactylus consobrinus (Peters, 1871)

(Documented as Cyrtodactylus cf. consobrinus in Teo \& Rajathurai, 1997)

Vernacular Name: Peter's Bent-toed Gecko

Previously believed to be restricted to BTNR, a new population (four records) was found by a stream running parallel to the pipeline reserve from park connector to Zhenghua Nature Park to Dairy Farm Road. Within BTNR, there were only three records, whereas Rajathurai \& Teo (1998) recorded 20.

11. Cyrtodactylus majulah Grismer, Wood \& Lim, 2012

Vernacular Name: Singapore Bent-toed Gecko

Described as a new species in 2012 (Grismer et al., 2012), this is an addition to 
BTNR's checklist. There was a single record at the eastern part of the reserve. It is also found in CCNR (Grismer et al., 2012; Groenewoud, 2015) and Admiralty Park (Law, 2017).

Cyrtodactylus quadrivirgatus was included in Teo \& Rajathurai (1997) based on a record of one that had climbed onto a car and "hitch-hiked" to BTNR from Panti, South Johor. Due to revisions in the taxonomy of bent-toed geckoes in the region (Grismer, 2011), the identity of the record can no longer be ascertained as there were no supporting voucher specimen or photographs and the species has been dropped from the updated checklist. For the same reason, previous records from CCNR should also be scrutinised. The species has, however, been confirmed to be present in the Upper Seletar Reservoir Park (Law et al., 2016).

12. Gehyra mutilata (Wiegmann, 1834)

Vernacular Name: Four-clawed Gecko

Usually found in association with human habitation, this species was recorded twice, which compares with the singleton by Rajathurai \& Teo (1998).

\section{Gekko monarchus (Schlegel, 1836)}

Vernacular Name: Spotted House Gecko

There were 44 records of this common gecko while 17 were noted by Rajathurai \& Teo (1998).

\section{Gekko smithii Gray, 1842}

Vernacular Name: Large Forest Gecko

This was not recorded, in contrast to the 15 documented by Rajathurai \& Teo (1998).

There have been no recent records from CCNR either.

\section{Hemidactylus craspedotus Mocquard, 1890}

(Documented as Cosymbotes craspedotus in Teo \& Rajathurai, 1997)

Vernacular Name: Frilly Gecko

The first record of this gecko in BTNR was noted by Rajathurai \& Teo (1998), and it was subsequently reported by Chua (2014) and Chua (2017). There were two records from the Survey. This species has probably been overlooked due to its cryptic camouflage. 
16. Hemidactylus frenatus Duméril \& Bibron, 1836

Vernacular Name: Spiny-tailed House Gecko

This species is common across Singapore, especially in built-up areas. There were 19 records.

17. Hemidactylus platyurus (Schneider, 1797)

(Documented as Cosymbotes platyurus in Teo \& Rajathurai, 1997)

Vernacular Name: Flat-tailed Gecko

The total of 30 reported by Teo \& Rajathurai (1997) was erroneous: only one at the Visitor Centre was indicated by Rajathurai \& Teo (1998). A human commensal, this gecko is usually found in built-up areas on buildings and structures and was not sighted during the Survey.

18. Hemiphyllodactylus typus Bleeker, 1860

Vernacular Name: Lowland Dwarf Gecko

This is an addition to the checklist. Probably often overlooked, this tiny gecko was recorded thrice. It is also found in the Western Catchment Area (Baker \& Lim, 2012; R.C.H. Teo, pers. obs., 2005-2007), Bidadari Park (Thomas, 2013a), at Pasir Ris Park (Tay \& Wind, 2013) and on Pulau Ubin (based on a photograph of one caught by a Mangrove Blue Flycatcher, Cyornis rufigastra, in the Chek Jawa Wetlands in 2010). It was also found in the mangroves at Mandai in 1993 (Lim, 1993)

\section{Family Scincidae}

19. Dasia grisea (Gray, 1845)

(Documented as Dasia cf. grisea in Teo \& Rajathurai, 1997)

Vernacular Name: Brown Tree Skink

Rajathurai \& Teo (1998) did not record this - it was first reported for BTNR by Baker $\& \operatorname{Lim}(2012)$. There were two records from the Survey.

20. Dasia olivacea Gray, 1839

Vernacular Name: Olive Tree Skink

This was not found during the Survey - three were recorded by Teo \& Rajathurai (1997). The species has also been recorded on Upper Thomson Road on the opposite side of the Central Catchment (Baker, 2014a). 
21. Eutropis multifasciatus (Kuhl, 1820)

(Documented as Mabuya multifasciata in Teo \& Rajathurai, 1997)

Vernacular Name: Many-lined Sun Skink

There were 50 records of this common species that is widely distributed through Singapore. Rajathurai \& Teo (1998) recorded 32.

22. Eutropis rugifera (Stoliczka, 1870)

(Documented as Mabuya rugifera in Teo \& Rajathurai, 1997)

Vernacular Name: Striped Sun Skink

The Survey documented three records, which compares with the two reported by Rajathurai \& Teo (1998).

23. Lygosoma bowringii (Günther, 1864)

(Documented as Riopa bowringi in Teo \& Rajathurai, 1997)

Vernacular Name: Garden Supple Skink

This was not found during the Survey. There was a single record by Rajathurai \& Teo (1998).

\section{Lipinia vittigera (Boulenger, 1894)}

Vernacular Name: Striped Tree Skink

There were two records while Rajathurai \& Teo (1998) recorded four. It has also been found in the grounds of the Singapore Night Safari (R.C.H. Teo, pers. obs., 2006).

\section{Family Varanidae}

25. Varanus nebulosus (Gray, 1831)

Vernacular Name: Clouded Monitor

In contrast to only two records by Rajathurai \& Teo (1998), there were 55 sightings. It was also found in Dairy Farm Nature Park and Hindhede Nature Park. Teo \& Rajathurai (1997) believed this species to be confined to BTNR and CCNR, but it is now known to be more widespread, with established populations on Pulau Ubin (R.C.H. Teo, pers. obs., 1998-2018), Pulau Tekong (Lim et al., 2016, R.C.H. Teo, pers. obs., 2001-2002) and Singapore Botanic Gardens (Thomas, 2013b; R.C.H. Teo, pers. obs., 2013-2018), and has also been recorded from Bukit Batok Nature Park (Baker \& Lim, 2012). 
26.Varanus salvator (Laurenti, 1768)

Vernacular Name: Malayan Water Monitor

There were two records of this species which is usually associated with open waterbodies and waterways. One was recorded by Rajathurai \& Teo (1998)

\section{Family Pythonidae}

27. Malayopython reticulatus (Schneider, 1801)

(Documented as Python reticulatus in Teo \& Rajathurai, 1997)

Vernacular Name: Reticulated Python

The largest snake in Singapore, this was recorded twice. Rajathurai \& Teo (1998) also had two records.

\section{Family Colubridae}

28. Ahaetulla fasciolata (Fischer,1885)

Vernacular Name: Speckle-headed Whip Snake

This was not sighted during the Survey, but there were recent records in BTNR (Chow, 2017) and Singapore Botanic Gardens (Sim \& Sim, 2017). There was a single record from BTNR by Teo \& Rajathurai (1997), but none from CCNR.

29. Ahaetulla mycterizans (Linnaeus, 1758)

Vernacular Name: Malayan Whip Snake

This is the usual Ahaetulla species encountered in the forest. There were 20 records within BTNR and another five in Dairy Farm Nature Park. Most, if not all, records in Teo \& Rajathurai (1997) of Ahaetulla prasina could have been this species instead. This is included as an addition to the checklist.

30. Ahaetulla prasina (Boie, 1827)

Vernacular Name: Oriental Whip Snake

There were four records of this snake, which is more commonly found in forest edges, parks and disturbed areas. See note under Ahaetulla mycterizans for possible misidentification in Teo \& Rajathurai (1997). 


\section{Boiga cynodon (Boie, 1827)}

Vernacular Name: Dog-toothed Cat Snake

This large snake was not sighted in the Survey. There were two reported by Rajathurai \& Teo (1998). It has been recorded from Pulau Tekong (Baker \& Lim, 2012; Lim et al., 2016) and Pulau Ubin (Baker \& Lim, 2012; R.C.H. Teo, pers. obs., 2001-2007).

\section{Boiga dendrophila (Boie, 1827)}

Vernacular Name: Gold-ringed Cat Snake

There were two records of this species, which can also be found on Pulau Tekong (Lim et al., 2016) and Pulau Ubin (M. Yusoff, pers. comm., 2000). Rajathurai \& Teo (1998) recorded two in BTNR.

\section{Calamaria lumbricoidea Boie, 1827}

Vernacular Name: Variable Reed Snake

Although three were recorded by Rajathurai \& Teo (1998), this was not detected during the Survey. It has been found at the Singapore Night Safari (Tan \& Yeo, 2013) and Upper Seletar Reservoir Park (Baker, 2014b).

34. Calamaria schlegeli Dumeril, Bibron \& Dumeril, 1854

Vernacular Name: Pink-headed Reed Snake

In contrast to the eight documented by Rajathurai \& Teo (1998), the Survey did not produce any record of this species. It is also known from Holland Woods (Teo \& Rajathurai, 1997).

\section{Chrysopelia paradisi Boie, 1827}

\section{Paradise Tree Snake}

There was a single record of this highly attractive snake. Four were recorded by Rajathurai \& Teo (1998). This snake is common around parks and gardens and is widespread in Singapore.

\section{Chrysopelia pelias (Linnaeus, 1758)}

Vernacular Name: Twin-barred Tree Snake

The single record of a roadkill compares with one record by Rajathurai \& Teo (1998). It was also sighted twice in Hindhede Nature Park during the Survey. 
37. Coelognathus flavolineatus (Schlegel, 1837)

(Documented as Elaphe flavolineata in Teo \& Rajathurai, 1997)

Vernacular Name: Common Malayan Racer

This species was not detected. Rajathurai \& Teo (1998) reported a single sighting. Baker \& Lim (2012) listed this as a widespread species in Singapore. It has been recorded from Pulau Ubin in 2016 (R.C.H. Teo, pers. obs.) and Pulau Tekong (Lim et al., 2016).

38. Dendrelaphis caudolineatus (Gray, 1834)

Vernacular Name: Striped Bronzeback

There were three records of this widespread species, which compares with four by Rajathurai \& Teo (1998). It was also seen once in Dairy Farm Nature Park.

39. Dendrelaphis cyanochloris (Wall, 1921)

Vernacular Name: Blue Bronzeback

This species was recorded once and is an addition to the checklist of BTNR. Its possible presence in Singapore was first noted by Baker \& Lim (2012), and it has been recorded in CCNR (Thomas, 2014).

40. Dendrelaphis formosus (Boie, 1827)

Vernacular Name: Elegant Bronzeback

Once recorded. Rajathurai \& Teo (1998) reported three, but it is uncertain if these were confused with Dendrelaphis kopsteini.

41. Dendrelaphis kopsteini Vogel \& van Rooijen, 2007

Vernacular Name: Kopstein's Bronzeback

There were two records of this snake - an addition to BTNR's checklist. This species was formerly confused with Dendrelaphis formosus and was described as a new species in 2007 (Vogel \& van Rooijen, 2007).

42. Dendrelaphis pictus (Gmelin, 1789)

Vernacular Name: Painted Bronzeback

There was only a single record of this snake, similar to what was recorded by Rajathurai \& Teo (1998). 
43. Dryocalamus subannulatus (Dumeril, Bibron \& Dumeril, 1854)

Vernacular Name: Malayan Bridle Snake

One was observed ascending a tree at night. Rajathurai \& Teo (1998) also had a single record.

44. Gongylosoma baliodeirus Boie, 1827

(Documented as Liopeltis baliodeirus in Teo \& Rajathurai, 1997)

Vernacular Name: Orange-bellied Ringneck

Although none was found during the Survey, there was a record in 2012 (N.J. Thomas, pers. obs.) of one among some wooden logs close to the Visitor Centre. Rajathurai \& Teo (1998) also recorded one.

45. Gonyosoma oxycephalum (Boie, 1827)

(Documented as Gonyosoma oxycephala in Teo \& Rajathurai, 1997)

Vernacular Name: Red-tailed Racer

There were two records of this arboreal snake; both individuals were asleep high in a tree. Rajathurai \& Teo (1998) had a single record. There are records from Pulau Tekong and the western part of Singapore (Lim et al., 2016).

46. Lycodon capucinus (Boie, 1827)

(Documented as Ophites aulicus in Teo \& Rajathurai, 1997)

Vernacular Name: House Wolf Snake

Rajathurai \& Teo (1998) had a single record of this highly urban snake, but none was found during the Survey.

47. Oligodon octolineatus (Schneider, 1801)

Vernacular Name: Striped Kukri Snake

There was no record of this snake, which was documented twice by Rajathurai \& Teo (1998).

48. Oligodon signatus (Gunther, 1864)

Vernacular Name: Barred Kukri Snake

The single record compares with the one by Rajathurai \& Teo (1998). 
49. Pseudorabdion longiceps (Cantor, 1847)

Vernacular Name: Dwarf Reed Snake

There were two records, while Rajathurai \& Teo (1998) reported one. This species is also found in Pulau Tekong (Lim et al., 2016; R.C.H. Teo, pers. obs. 2001-2002) and Pulau Ubin (Thomas et al., 2015).

50. Ptyas carinata (Gunther, 1858)

(Documented as Ptyas carinatus in Teo \& Rajathurai, 1997)

Vernacular Name: Keeled Rat Snake

In contrast to ten reported by Rajathurai \& Teo (1998), only one was recorded for the Survey.

51. Ptyas fusca (Gunther, 1858)

(Documented as Zaocys fuscus in Teo \& Rajathurai, 1997)

Vernacular Name: White-bellied Rat Snake

This snake is usually associated with forest streams - three were recorded by different streams. This is an addition to the checklist for BTNR, the records by Teo \& Rajathurai (1997) being from CCNR.

52. Ptyas korros (Schlegel, 1837)

Vernacular Name: Indochinese Rat Snake

This species was included in the checklist by Rajathurai \& Teo (1998) from a single record in 1993, but there have been no records since.

53. Sibynophis melanocephalus (Gray, 1835)

Vernacular Name: Black-headed Collared Snake

Rajathurai \& Teo (1998) had two records, but it was not found during the Survey. It has also been recorded from Pulau Ubin in 2009 (R.C.H. Teo, pers. obs.), Pulau Tekong (Lim et al., 2016) and Upper Peirce Reservoir Park (Lee, 2015).

54. Xenelaphis hexagonotus (Cantor, 1847)

Vernacular Name: Malayan Brown Snake

Rajathurai \& Teo (1998) reported one, but none was sighted during the Survey. 


\section{Family Natricidae}

55. Macropisthodon rhodomelas (Boie, 1827)

Vernacular Name: Blue-necked Keelback

There was no record, whereas Rajathurai \& Teo (1998) recorded two.

56. Xenochrophis maculatus (Edeling, 1864)

Vernacular Name: Spotted Keelback

Included in the checklist by Rajathurai \& Teo (1998) from a single record of a roadkill in 1989 , this species was not detected during the present Survey.

\section{Family Elapidae}

57. Calliophis bivirgatus (Boie,1847)

(Documented as Maticora bivirgata in Teo \& Rajathurai, 1997)

Vernacular Name: Blue Malayan Coral Snake

In contrast to the 13 records by Rajathurai \& Teo (1998), only one was sighted here.

58. Calliophis intestinalis (Laurenti,1768)

(Documented as Maticora intestinalis in Teo \& Rajathurai, 1997)

Vernacular Name: Banded Malayan Coral Snake

The Survey did not produce any record of this species. Rajathurai \& Teo (1998) recorded four. It has been found in Kent Ridge Park (Lim, 2014) and Pulau Tekong (Lim et al., 2016).

59. Naja sumatrana Muller, 1890

Vernacular Name: Equatorial Spitting Cobra

This snake is usually encountered along the forest edge and open habitats. While Rajathurai \& Teo (1998) recorded four, only one was encountered during the Survey at the edge of BTNR. 


\section{Family Viperidae}

60. Tropidolaemus wagleri (Boie, 1827)

Vernacular Name: Wagler's Pit Viper

There were 23 records, well spread around BTNR. This contrasts to only five by Rajathurai \& Teo (1998). It was also recorded in the adjacent Dairy Farm Nature Park and Hindhede Nature Park. There was a record in 1985 from Pulau Tekong (Lim et al., 2016).

\section{CLASS MAMMALIA \\ ORDER PHOLIDOTA \\ Family Manidae}

1. Manis javanica Desmarest, 1822

Vernacular Name: Sunda Pangolin

There were two records in the western periphery of BTNR. A female with a juvenile was also found in Hindhede Nature Park. Rajathurai \& Teo (1998) documented a single record.

\section{ORDER INSECTIVORA Family Soricidae}

2. Crocidura malayana Robinson \& Kloss, 1911

(Documented as C. cf. fuliginosa in Teo \& Rajathurai, 1997)

Vernacular Name: Malayan White-toothed Shrew

There was no record for this species as pitfall trapping was not deployed. There was, however, a recent record from a pitfall trap in the adjacent Hindhede Nature Park (Y.F. Chung, pers. comm.). Rajathurai \& Teo (1998) recorded 21 from pitfall trapping.

\section{ORDER SCANDENTIA \\ Family Tupaiidae}

3. Tupaia glis (Diard, 1820)

Vernacular Name: Common Treeshrew

In comparison to 323 recorded by Rajathurai \& Teo (1998), there were 236 records. It is still the dominant diurnal mammal of the forest floor and accounted for $64 \%$ (87 
records) of all small mammal trapping. Although the main populations of this species are within BTNR and CCNR, it is also common in the Western Catchment Area (R.C.H. Teo, pers. obs., 2001-2002).

\section{ORDER DERMOPTERA \\ Family Cynocephalidae}

\section{Galeopterus variegatus (Audebert, 1799)}

(Documented as Cynocephalus variegatus in Teo \& Rajathurai, 1997)

Vernacular Name: Malayan Colugo

This was frequently encountered, with 141 sightings, in contrast to the 39 recorded by Rajathurai \& Teo (1998). It has also been extending in range to the immediate vicinity of BTNR, as evidenced by 15 records from Hindhede Nature Park, seven records from Dairy Farm Nature Park, four records from Kampong Trail and a possible roadkill on Bukit Drive (Lim, 2014). Other than BTNR and CCNR, the species has also been found in Bukit Batok Nature Park (Yeo, 2014), Swiss Club Road (Briffet, 1989), Mandai Lake Road (Tan, 2014) and, surprisingly, Changi (Seow, 2011). Using distance-sampling, Lim \& Ng (2010) estimated the population density within BTNR and CCNR to be $0.535( \pm 0.104)$ individuals per hectare and that the total population was $1,074 \pm 209$ individuals.

\section{ORDER CHIROPTERA Family Pteropodidae}

\section{Cynopterus brachyotis (Müller, 1838)}

Vernacular Name: Lesser Dog-faced Fruit Bat

This was not trapped in mist nets or harp traps, but there were 13 sightings of Cynopterus sp., which were presumed to be of this species. This contrasts with the 75 recorded by Rajathurai \& Teo (1998).

\section{Eonycteris spelaea (Dobson, 1871)}

Vernacular Name: Cave Nectar Bat

Over 100 were observed feeding on the flowers of a Petai (Parkia speciosa Hassk.) tree behind the Bukit Timah Visitor Centre. This is the first documented record from BTNR. Although the existence of a permanent roost near BTNR has been known since 1997 (Teo \& Rajathurai, 1997), there had been no prior records of this nectarivorous bat within the reserve. This species is widespread in Singapore (Baker \& Lim, 2012) and has also been recorded on Pulau Ubin, based on video footage in 2006, showing 
one brought by a male Oriental Pied Hornbill, Anthracoceros albirostris, to its nest (R.C.H. Teo, pers. obs.)

7. Penthetor lucasi (Dobson, 1880)

Vernacular Name: Dusky Fruit Bat

In contrast to the 123 recorded by Rajathurai \& Teo (1998), there were only two records, including one that was mist-netted. The species is restricted to BTNR.

8. Pteropus vampyrus (Linnaeus, 1758)

Vernacular Name: Malayan Flying Fox

A single sighting compares to the two recorded by Rajathurai \& Teo (1998). This was likely a visitor from Malaysia or Indonesia as no colony has been found in Singapore in recent times.

\section{Family Emballonuridae}

9. Emballonura monticola Temminck, 1838

Vernacular Name: Lesser Sheath-tailed Bat

Pottie (1996) rediscovered this species in BTNR where up to six bats were found roosting under an overhanging rock. It has not been detected at BTNR since, but Thomas \& Tan (2016) found one on Pulau Ubin. It is presently not known to occur in CCNR.

10. Saccolaimus saccolaimus (Temminck, 1838)

Vernacular Name: Pouched Tomb Bat

Rajathurai \& Teo (1998) reported this at the fringes of BTNR (over the Visitor Centre and pipeline reserve area at the eastern edge of BTNR). It was not found within BTNR in the Survey but was observed near the outskirts of the reserve.

\section{Family Rhinolophidae}

11. Rhinolophus lepidus Blyth, 1844

Vernacular Name: Blyth's Horsehoe Bat

Bioacoustic surveys frequently detected this species under the forest canopy throughout BTNR. There were 29 trapping records, and another 40 were observed near 
a roost. Based on observations of bat streams at dusk, there are at least three roosting colonies within BTNR. It was also detected in the adjacent Hindhede Nature Park. Rajathurai \& Teo (1998) documented 490 records based on visual counts at a flyway across Main Road and by trapping.

\section{Family Hipposideridae}

12. Hipposideros bicolor (Temminck, 1834)

Vernacular Name: Bicoloured Roundleaf Bat

This species was rediscovered by Leong \& Lim (2009) in BTNR, where four records were obtained in 2008. It was not detected during the Survey. The species is presently known only from BTNR.

\section{Family Vespertiniolidae}

13. Myotis muricola (Gray, 1864)

Vernacular Name: Whiskered Myotis

This species was detected through bioacoustic surveys along the Main Road. Six were reported by Rajathurai \& Teo (1998).

\section{Pipistrellus stenopterus (Dobson, 1875)}

Vernacular Name: Narrow-winged Pipistrelle

Although not detected during the Survey, Leong et al. (2010) documented the presence of this species in BTNR through a single specimen collected near the Visitor Centre. This is an addition to the checklist for BTNR.

\section{Scotophilus kuhlii Leach, 1821}

Vernacular Name: Lesser Asiatic Yellow House Bat

This common species was frequently detected in open areas, forest gaps and over the forest canopy.

\section{Tylonycteris pachypus (Temminck, 1840)}

Vernacular Name: Lesser Bamboo Bat

There has been no record of this since its rediscovery at BTNR by Teo \& Rajathurai (1997). 
17. Tylonycteris robustula Thomas, 1915

Vernacular Name: Greater Bamboo Bat

Although 34 were recorded by Rajathurai \& Teo (1998), this was not detected in the Survey.

\section{Family Molossidae}

18.Cheiromeles torquatus, Horsfield, 1824

Vernacular Name: Greater Naked Bat

This was not detected, but Leong et al. (2009) recorded the occurrence of this species in BTNR. It has also been found at Sembawang (Leong, 2014). This is an addition to the checklist.

\section{ORDER PRIMATES \\ Family Lorisidae}

19. Nycticebus coucang (Boddaert, 1785)

Vernacular Name: Sunda Slow Loris

The seven sightings constituted the first records of this species for BTNR. The single record by Teo \& Rajathurai (1997) was considered an escapee as it was found in a residential property at the edge of BTNR (Rajathurai \& Teo, 1998). A sizeable population exists on Pulau Tekong (Lim et al., 2016).

\section{Family Cercopithecidae}

20. Macaca fascicularis (Raffles, 1821)

Vernacular Name: Long-tailed Macaque

There were over 700 records of this common species, while 307 were recorded by Rajathurai \& Teo (1998). Close to 50\% of the records were from camera trapping and it is noted that many records were of the same social units visiting the sites repeatedly. In 2012, Riley et al. (2015) found seven social units in BTNR, with an estimated population of 198 individuals. 


\section{ORDER CARNIVORA \\ Family Viverridae}

\section{Arctogalidia trivirgata (Gray, 1832)}

Vernacular Name: Three-striped Palm Civet

Rajathurai \& Teo (1998) recorded two sightings of this civet (possibly the same individual) in BTNR. There were two records from the Survey

\section{Paradoxurus musangus (Raffles, 1821)}

(Documented as P. hermaphroditus in Teo \& Rajathurai, 1997)

Vernacular Name: Sumatran Palm Civet

This species was not recorded by Teo \& Rajathurai (1997) but the Survey produced 18 records, including a juvenile. This is an addition to BTNR's checklist. In recent years, animals removed from residential areas of Singapore have been released at various localities.

\section{ORDER ARTIODACTYLA \\ Family Suidae}

\section{Sus scrofa Linnaeus, 1758}

Vernacular Name: Eurasian Wild Pig

An addition to the checklist, there were 270 records across BTNR, particularly in the western part. Most records were from camera traps (1-7 pigs each time) and these were likely contributed by the same animals visiting the sites repeatedly. One was also recorded in Hindhede Nature Park. The species was not documented by Teo \& Rajathurai (1997) but has since become widespread and common in Singapore (Yong et al., 2015).

\section{Family Tragulidae}

24. Tragulus kanchil (Raffles, 1821)

(Documented as T. javanicus in Teo \& Rajathurai, 1997)

Vernacular Name: Lesser Mousedeer

Rajathurai \& Teo (1998) had a single record in 1997, but the Survey did not detect the species. 


\section{ORDER RODENTIA \\ Family Sciuridae}

25. Callosciurus notatus (Boddaert, 1785)

Vernacular Name: Plantain Squirrel

Found in forest, wooded areas, mangroves, parks and gardens and even roadside greenery, this common squirrel was recorded 251 times, in contrast to the 76 noted by Rajathurai \& Teo (1998).

26. Hylopetes spadiceus (Blyth, 1847)

Vernacular Name: Red-cheeked Flying Squirrel

First recorded for Singapore by Teo \& Rajathurai (1997), there were only three records in contrast to 25 by Rajathurai \& Teo (1998). This species has also been recently found in CCNR (Chua et al., 2013).

27. Iomys horsfieldii (Waterhouse, 1838)

Vernacular Name: Horsfield's Flying Squirrel

This species was rediscovered in 1995 in CCNR (Teo \& Rajathurai, 1997), but it was not detected at BTNR. The Survey found this to be common at BTNR, with 81 records. It is also found around the reserve, with six records from Dairy Farm Nature Park, and one each in Hindhede Nature Park and Kampong Trail. It has also been recorded in Bukit Batok Nature Park (Chua et al., 2013).

28. Ratufa affinis (Raffles, 1821)

Vernacular Name: Cream-coloured Giant Squirrel

This large squirrel has not been detected in BTNR since 1990. There have also been no recent records from CCNR.

29. Rhinosciurus laticaudatus (Müller, 1840)

Vernacular Name: Shrew-faced Ground Squirrel

Although there were no records from either Rajathurai \& Teo (1998) or the Survey, it was detected frequently in a concurrent camera trapping project at the eastern part of BTNR (Y.F. Chung, pers. comm.). Lim \& Yeo (2012) and Tan (2015) also recorded the species in BTNR; Lim \& Yeo (2012) also found it in CCNR. 
30. Sundasciurus tenuis (Horsfield, 1824)

Vernacular Name: Slender Squirrel

There were 220 records of this common squirrel. This contrasts with the 111 recorded by Rajathurai \& Teo (1998). It is restricted to BTNR and CCNR, Bukit Batok Nature Park and Singapore Botanic Gardens (Baker \& Lim, 2012).

\section{Family Muridae}

31. Maxomys surifer (Miller, 1900)

Vernacular Name: Red Spiny Rat

Last recorded in 1968 in BTNR, this species is presumed to have been extirpated from Singapore, with no records for about five decades.

32. Rattus annandalei (Bonhote, 1903)

Vernacular Name: Annandale's Rat

In contrast to the 104 recorded by Rajathurai \& Teo (1998), there were 59 records of this species, of which $64 \%(n=38)$ were from small mammal trapping.

33. Rattus tanezumi Temminck 1844 ,

(Documented as Rattus rattus in Teo \& Rajathurai, 1997).

Vernacular Name: Oriental House Rat

There were three records of this rat at the periphery of BTNR. This compares with the two documented by Rajathurai \& Teo (1998).

34. Rattus tiomanicus (Miller, 1900)

Vernacular Name: Malaysian Wood Rat

Although eight were recorded by Rajathurai \& Teo (1998), only one was trapped during the Survey. 


\section{Family Hystricidae}

\section{Hystrix brachyura Linnaeus, 1758}

Vernacular Name: Malayan Porcupine

Chung et al. (2016) noted the presence of this species in BTNR, CCNR, Pulau Tekong, Pulau Ubin and the Western Catchment Area. Camera trapping produced 28 records in the western part of BTNR, contributed by at most three individuals.

\section{Discussion}

The Survey provided an update of the status of amphibian, reptile and mammal diversity at BTNR since the first baseline inventory established about two decades ago (Teo \& Rajathurai, 1997). Diversity of amphibians, reptiles and mammals at BTNR remains high - the Survey results of 18 amphibian, 41 reptile and 23 mammal species were quite comparable, in terms of species diversity, to Teo \& Rajathurai (1997), which documented 19 amphibian, 51 reptile and 26 mammal species. There were, however, significant differences in the species assemblage from the two surveys, resulting in 18 additions to the BTNR checklist. The current inventory stands at 115 species ever recorded there -21 amphibian, 60 reptile and 34 mammal species. A total of 49 species (44\% of 112 indigenous species) are listed as threatened in Singapore (Davison et al., 2008).

An analysis of the results shows that $61 \%$ of species (84\% of amphibians, $55 \%$ of reptiles, $57 \%$ of mammals) were documented by both Rajathurai \& Teo (1998) and the current Survey, while $21 \%$ (5\% of amphibians, $27 \%$ of reptiles, $20 \%$ of mammals) were reported only by Rajathurai \& Teo (1998), and 18\% (11\% of amphibians, $18 \%$ of reptiles, $23 \%$ of mammals) were recorded in the current Survey only.

\section{Dominant Species}

In and around streams and water bodies, the dominant anurans are Leptobrachium nigrops and Chalcorana labialis, and elsewhere on the forest floor, Kalophrynus limbooliati is the prevalent species.

Rattus annandalei remains as the primary nocturnal small mammal of the forest floor, while Tupaia glis was dominant during daylight hours. Up in the canopy, Callosciurus notatus and Sundasciurus tenuis are the commonest mammals, but the nocturnal niche is filled by Galeopterus variegatus and Iomys horsfieldii. Macaca fascicularis continues to be another dominant species, but Sus scrofa has become the largest dominant species at BTNR. The predominant bat within the forest canopy is Rhinolophus lepidus.

\section{Species at Risk}

The lack of records of the large Gekko smithi during the Survey might indicate its extirpation from BTNR. Due to its loud vocalisations, this species is usually detectable if present. 
The single record of Ratufa affinis from BTNR was in 1990 (Teo \& Rajathurai, 1997). As this is a large and conspicuous diurnal squirrel, there is a high probability that Ratufa affinis has been extirpated from BTNR, as well as Singapore, with the last records from CCNR in 1997.

The lack of records of Maxomys surifer from either BTNR or CCNR for about five decades despite intensive small mammal trapping and camera trapping indicates that the species can no longer be found in Singapore and can be presumed to have been extirpated.

\section{Other Noteworthy Species}

The seven records of Nycticebus coucang were widely spread across BTNR. It is not clear if these were part of a remnant, natural population or a result of release of animals confiscated from the illegal pet trade in Singapore, with or without the knowledge of government agencies.

Chasen (1925) recorded Iomys horsfieldii from Bukit Timah but this species was not found by Teo \& Rajathurai (1997). There appears to be a large population of this flying squirrel at BTNR, extending even to areas adjacent to the reserve, including Dairy Farm Nature Park and Kampong Trail. This nocturnal species could have been overlooked by Teo \& Rajathurai (1997), or confused with Hylopetes spadiceus, as many records of flying squirrels in Rajathurai \& Teo (1998) were assumed to be that species. During the Survey, volunteers were better able to differentiate the two species and identify them by call alone. Another possibility is that the population was much smaller in 1996-1997 but increased significantly in the past two decades.

The presence of a sizeable population of Sus scrofa at BTNR is of concern due to its rooting behaviour which might have negative impacts on important ground flora and seedlings of forest trees. This species has presumably colonised BTNR from other areas in Singapore through connecting vegetated corridors.

The 18 widely distributed records of Paradoxurus musangus indicates an established population within the reserve. As with Nycticebus coucang, this could either be a remnant, natural population or an introduced one, as both species are common targets of the illegal pet trade.

ACKNOWLEDGEMENTS. The Survey was only possible with the help of many volunteers in the field: NParks: Benjamin Paul Lee, Benjamin Lee Chengfa, Cheryl Chia, Cyrena Lin, Germaine Leng, Gloria Seow, Holly Siow, Ivan Kwan, James Gan, Jacky Soh, Jayasri Lakshminarayanan, John Wei, Jeanne Tan, Joseph Lin, Leroy Alphonso, Lim Siew Hong, Mishak Shunari, Mohd Azlin bin Sani, Robin Ngiam, Rushan bin Abdul Rahman, Shirley Wong, Spykerman Shaun Adam. HSBC: Carmen Choy, Casey Ng, Ernest Soh, Esther Chow, Matt Chan, Ong Ya-Yi, Patrick Chong, Shyamsundar Veeraraghavan, Steven Pereira.Others: Amanda Tan, Angus Lamont, Audrey Lee, Chan Kwok Wai, Cherry Goh, Chloe Tan, Claudia Tan, Fung Tze Kwan, Gloria Seow, Jocelyn Yeo, Joey Gan, Joleen Chan, Joys Tan, Law Ing Sind, Law Ingg Thong, Lee Juin Bin, Lee King Li, Marcus Chua, Mary-Ruth Low, Ng Bee Choo, Nick Baker, Rebecca Lee, Sankar Ananthanarayanan, Serin Subaraj, Subaraj Rajathurai, Tan Hui Zhen, Teresa Teo Guttensohn, Timothy Pwee, Vilma D’Rozario, and Yeo Suay Hwee. Logistics support was provided by staff of the Central Nature Reserve Branch, NParks. 


\section{References}

Baker, N. (2014a). Olive tree skink roadkill at Old Upper Thomson Road. Singapore Biodivers. Rec. 2014: 297.

Baker, N. (2014b). Variable reed snake swallows earthworm. Singapore Biodivers. Rec. 2014: 23-24.

Baker, N. \& Lim, K.K.P. (2012). Wild Animals of Singapore. A Photographic Guide to Mammals, Retiles, Amphibians and Freshwater Fishes, updated edition. Singapore: Draco Publishing and Distribution Pte. Ltd. and The Nature Society (Singapore).

Briffett, C. (1989). The Flying Lemur. Pangolin 2(1): 7-12.

Chan, L. \& Davison, G.W.H. (2019). Introduction to the Comprehensive Biodiversity Survey of Bukit Timah Nature Reserve, Singapore, 2014-2018. Gard. Bull. Singapore 71 (Suppl. 1): 3-17.

Chan, S.H. \& Goh, C. (2010). Frogs of Sungei Buloh Wetland Reserve (Amphibia: Anura). Nat. Singapore 3: 103-116.

Chasen, F.N. (1925). A Preliminary Account of the Mammals of Singapore Island. Singapore Nat. 5: 74-89.

Chia, C.S.W. \& Soh, Z. (2014). Black-bearded Flying Dragon at Kampung Trail. Singapore Biodivers. Rec. 2014: 222.

Chow, L.S.Y. (2017). Speckle-headed whip snake at the Bukit Timah Nature Reserve. Singapore Biodivers. Rec. 2017: 17-18.

Chua, M.A.H. (2014). Frilly gecko at Bukit Timah Nature Reserve. Singapore Biodivers. Rec. 2014: 58.

Chua, M.A.H. (2017). Frilly gecko at Bukit Timah Nature Reserve. Singapore Biodivers. Rec. 2017: 69-70.

Chua, M.A.H., Baker, N., Yeo, R.K.H. \& Sivasothi, N. (2013). New locality records for two species of flying squirrels (Mammalia: Rodentia: Sciuridae) in Singapore. Nat. Singapore 6: 301-305.

Chung, Y.F., Lim, N.T.-L., Shunari, M., Wang D.J. \& Chan, S.K.L. (2016). Records of the Malayan porcupine, Hystrix brachyura (Mammalia: Rodentia: Hystricidae) in Singapore. Nat. Singapore 9: 63-68.

Davison, G.W.H., Ng, P.K.L. \& Ho, H.C. (eds) (2008). The Singapore Red Data Book: Threatened Plants and Animals of Singapore, $2^{\text {nd }}$ ed. Singapore: The Nature Society (Singapore).

Figueroa, A. \& Selveindran, P.M. (2011). A new locality for the thorny bush frog, Theloderma horridum Boulenger (Amphibia: Anura: Rhacophoridae) in Singapore. Nat. Singapore 4: 259-262.

Grismer, L.L. (2011). Lizards of Peninsular Malaysia, Singapore, and their Adjacent Archipelogos. Frankfurt am Main: Edition Chimaira.

Grismer, L.L., Wood, P.L. Jr. \& Lim, K.K.P. (2012). Cyrtodactylus majulah, a new species of bent-toed gecko (Reptilia: Squamata: Gekkonidae) from Singapore and the Riau Archipelago. Raffles B. Zool. 60(2): 487-499.

Groenewoud, X. (2015). Singapore bent-toed gecko swimming underwater. Singapore Biodivers. Rec. 2015: 42.

Law, I.S. (2017). Singapore bent-toed gecko at Admiralty Park. Singapore Biodivers. Rec. 2017: 77. 
Law, I.S., Law, I.T. \& Subaraj, S. (2016). Marbled bent-toed gecko at Upper Seletar. Singapore Biodivers. Rec. 2016: 117-118.

Lee, H.S. (2015). Black-headed collared snake at Upper Peirce Reservoir Park. Singapore Biodivers. Rec. 2015: 62.

Leong, T.M. (2014). Naked bulldog bat from Sembawang. Singapore Biodivers. Rec. 2014: 182-184.

Leong, T.M. \& Lim, K.K.P. (2009). Noteworthy microchiropteran records from the Bukit Timah and Central Catchment Nature Reserves, Singapore. Nat. Singapore 2: 83-90.

Leong, T.M. \& Teo, S.C. (2009). Endotrophic tadpoles of the Saint Andrew's Cross Toadlet, Pelophyrne signata (Amphibia: Anura: Bufonidae) in Singapore. Nat. Singapore 2: 21-25.

Leong, T.M., Teo, S.C. \& Lim, K.K.P. (2009). The naked bulldog bat, Cheiromeles torquatus in Singapore-past and present records, with highlights on its unique morphology (Microchiroptera: Molossidae). Nat. Singapore 2: 215-230.

Leong, T.M., Shunari, M. \& Lim, K.K.P. (2010). The narrow-winged pipistrelle, Pipistrellus stenopterus (Dobson) in Singapore (Mammalia: Chiroptera: Vespertilionidae). Nat. Singapore 3: 159-165.

Lim, K.K.P. (ed.) 1993. Recent reports. Pangolin. 6(1-2): 1-4.

Lim, K.K.P. (2013). Malayan giant frog at Bukit Gombak. Singapore Biodivers. Rec. 2013: 112.

Lim, K.K.P. (2014). Banded Malaysian coral snake at Kent Ridge. Singapore Biodivers. Rec. 2014: 97.

Lim, K.K.P. \& Chua, M.A.H. (2014). Malayan giant frog at the Botanic Gardens. Singapore Biodivers. Rec. 2014: 27.

Lim, K.K.P., Chua, M.A.H. \& Lim, N.T.-L. (2016). Freshwater fishes, terrestrial herpetofauna and mammals of Pulau Tekong, Singapore. Nat. Singapore 9: 165-198.

Lim, N.T.-L. (2014). Sunda colugo carcass at Bukit Drive. Singapore Biodivers. Rec. 2014: 286-287.

Lim, N.T.-L. \& Ng, P.K.L. (2010). Population assessment methods for the Sunda colugo Galeopterus variegatus (Mammalia: Dermoptera) in tropical forsts and their viability in Singapore. Raffles B. Zool. 58(1): 157-164.

Lim, N.T.-L. \& Yeo, A.W.M. (2012). Records of the shrew-faced squirrel, Rhinosciurus laticaudatus (Mammalia: Rodentia: Sciuridae), in Singapore. Nat. Singapore 5: 165-170.

Lim, W.H., Li, T.J. \& Cai, Y. (2015). A new locality for the caecilian, Ichthyophis paucisulcus. Nat. Singapore 8: 73-75.

Ng, M.F.C. (2014). Peninsular rock gecko at Venus Drive. Singapore Biodivers. Rec. 2014: 293.

Pottie, S.A. (1996). Studies of the Ecology and Behaviour of Insectivorous Bat Species in Singapore. Unpublished M.Sc. thesis, School of Biological Sciences, National University of Singapore.

Rajathurai, S. \& Teo, R. (1998). Vertebrate diversity, abundance and distribution in the Bukit Timah Nature Reserve. Unpublished report submitted to the National Parks Board. 
Riley, C.M., Jayasri, S.L. \& Gumert, M.D. (2015). Results of a nationwide census of the long-tailed macaque (Macaca fascicularis) population of Singapore. Raffles B. Zool. 63: 503-515.

Seow, G. (2011). Colugo encounter near Changi Village. Nature News, The Newsletter of the Nature Society (Singapore) Jul-Aug 2011: 5.

Sim, K. \& Sim, N. (2017). Speckle-headed whip snake at the Botanic Gardens. Singapore Biodivers. Rec. 2017: 94-95.

Siow, H., Low, M.-R. \& Wei, J.J. (2014). Masked rough-sided frog at Holland Woods. Singapore Biodivers. Rec. 2014: 105.

Tan, D.J.X. (2015). Shrew-faced squirrel at Bukit Timah. Singapore Biodivers. Rec. 2015: 39.

Tan, H.H. (2014). Malayan colugo at Mandai Lake Road. Singapore Biodivers. Rec. 2014: 117.

Tan, H.H. \& Yeo, D.C.J. (2013). Variable reed snake attempting to swallow earthworm. Singapore Biodivers. Rec. 2013: 10.

Tay, A. \& Wind, C. (2013). Lowland dwarf gecko at Pasir Ris mangroves. Singapore Biodivers. Rec. 2013: 101.

Teo, R. (2003). Rare finds in the Gardens: Frog in the Dell. Gardenwise 20: 6.

Teo, R.C.H. \& Rajathurai, S. (1997). Mammals, reptiles and amphibians in the nature reserves of Singapore - diversity, abundance and distribution. Proceedings of the Nature Reserves Survey Seminar. Gard. Bull. Singapore 49: 353-425.

Thomas, N. (2013a). Lowland dwarf gecko at Bidadari. Singapore Biodivers. Rec. 2013: 70.

Thomas, N. (2013b). Clouded monitor lizards at the Singapore Botanic Gardens. Singapore Biodivers. Rec. 2013: 44-45.

Thomas, N. (2014). Blue bronzeback at MacRitchie forest. Singapore Biodivers. Rec. 2014: 5.

Thomas, N. \& Tan, J. (2016). Resdiscovery of the lesser sheath-tailed bat on Pulau Ubin. Singapore Biodivers. Rec. 2016: 63-64.

Thomas, N., Yeo, H.H.T., Fung, T.K. \& Low, M.-R. (2015). Dwarf reed snakes on Pulau Ubin. Singapore Biodivers. Rec. 2015: 5.

Vogel, G. \& van Rooijen, J. (2007). A new species of Dendrelaphis (Serpentes: Colubridae) from Southeast Asia. Zootaxa 1394: 25-45.

Yeo, R.K.H. (2014). Malayan colugo at Bukit Batok Nature Park. Singapore Biodivers. Rec. 2014: 89.

Yong, D.L., Lee, B.P.Y.H., Ang, A. \& Tan, K.H. (2015). The status on Singapore island of the Eurasian wild pig Sus scrofa (Mammalia: Suidae). Nat. Singapore 3: 227-237. 


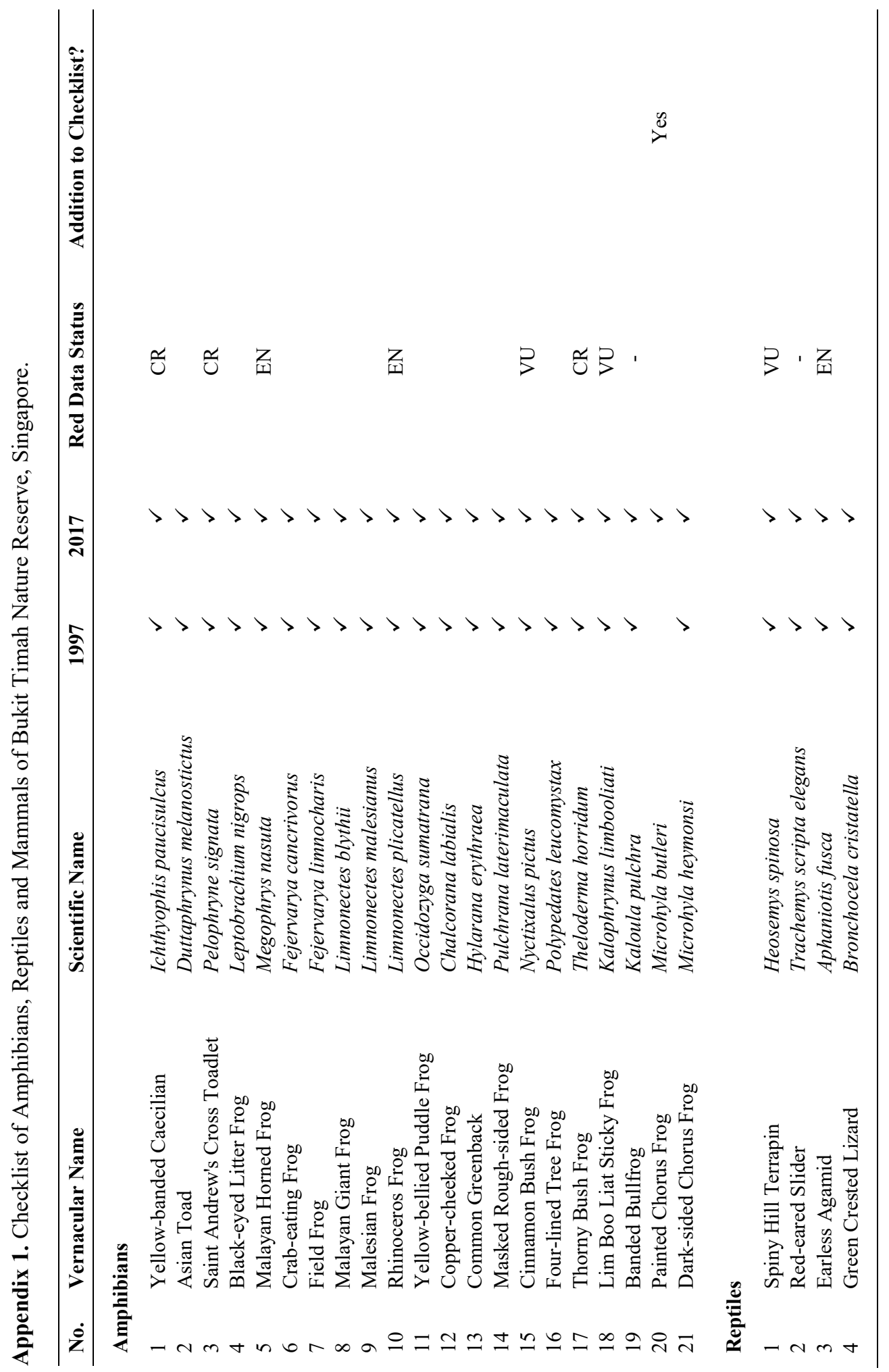




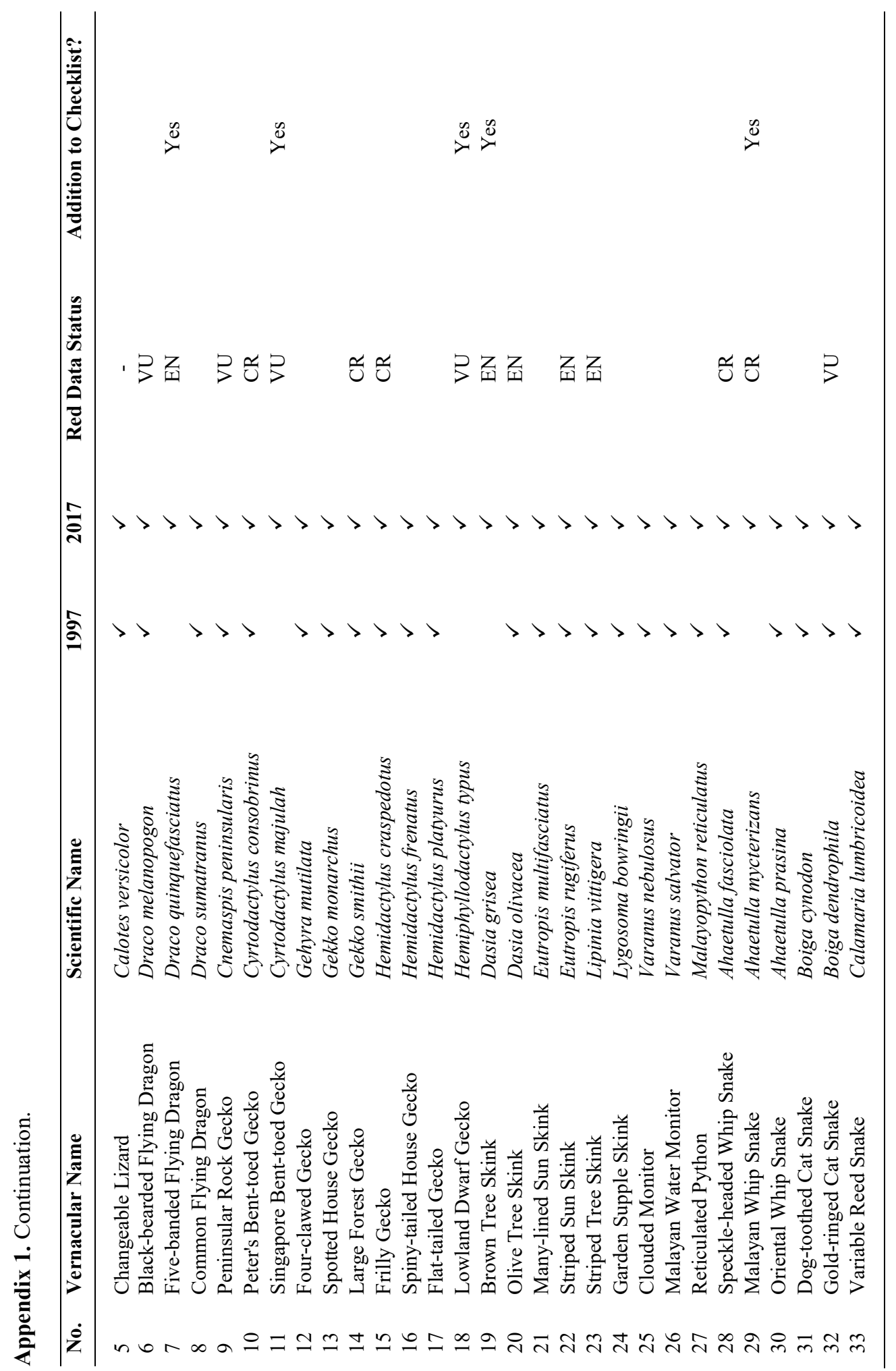




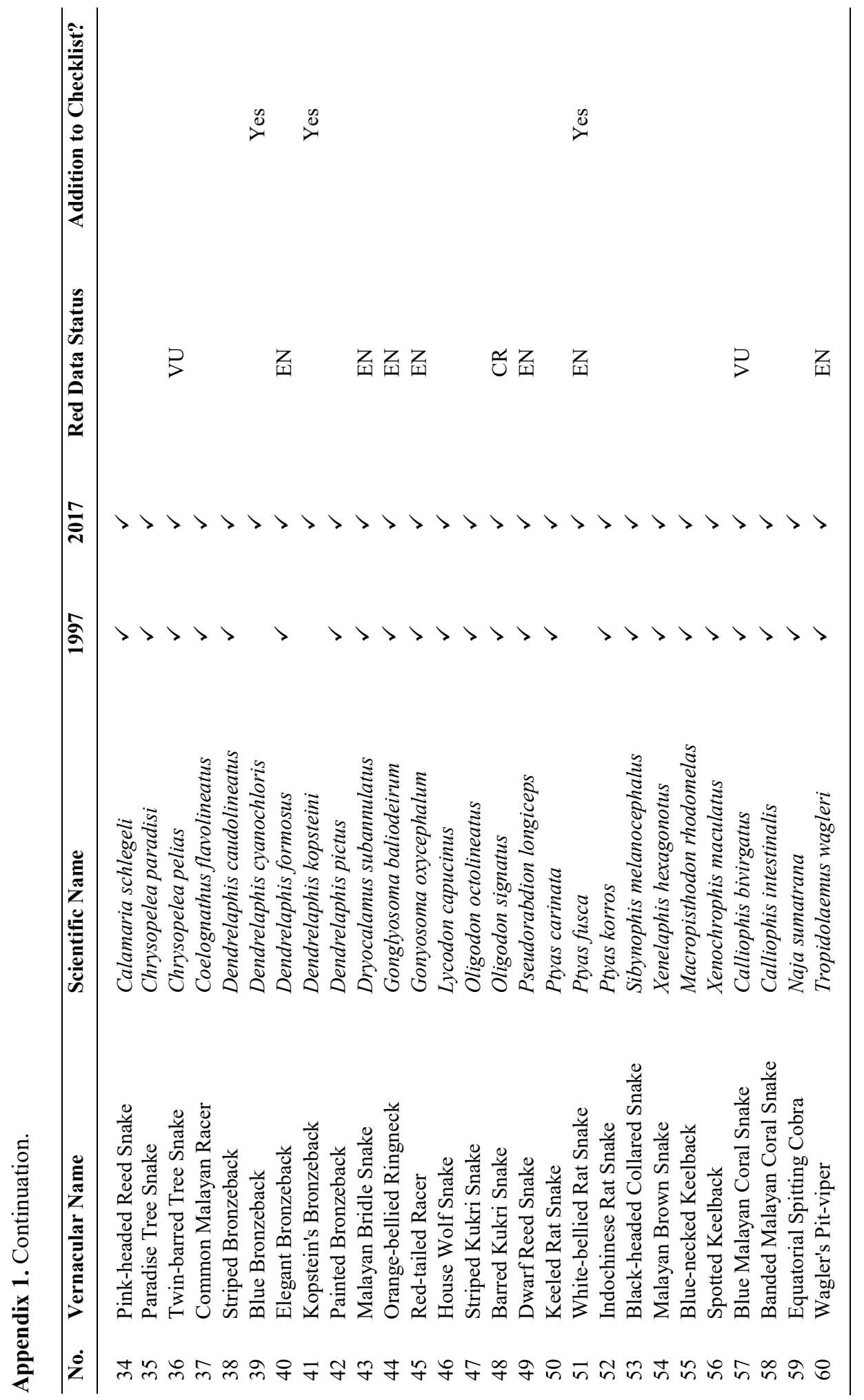




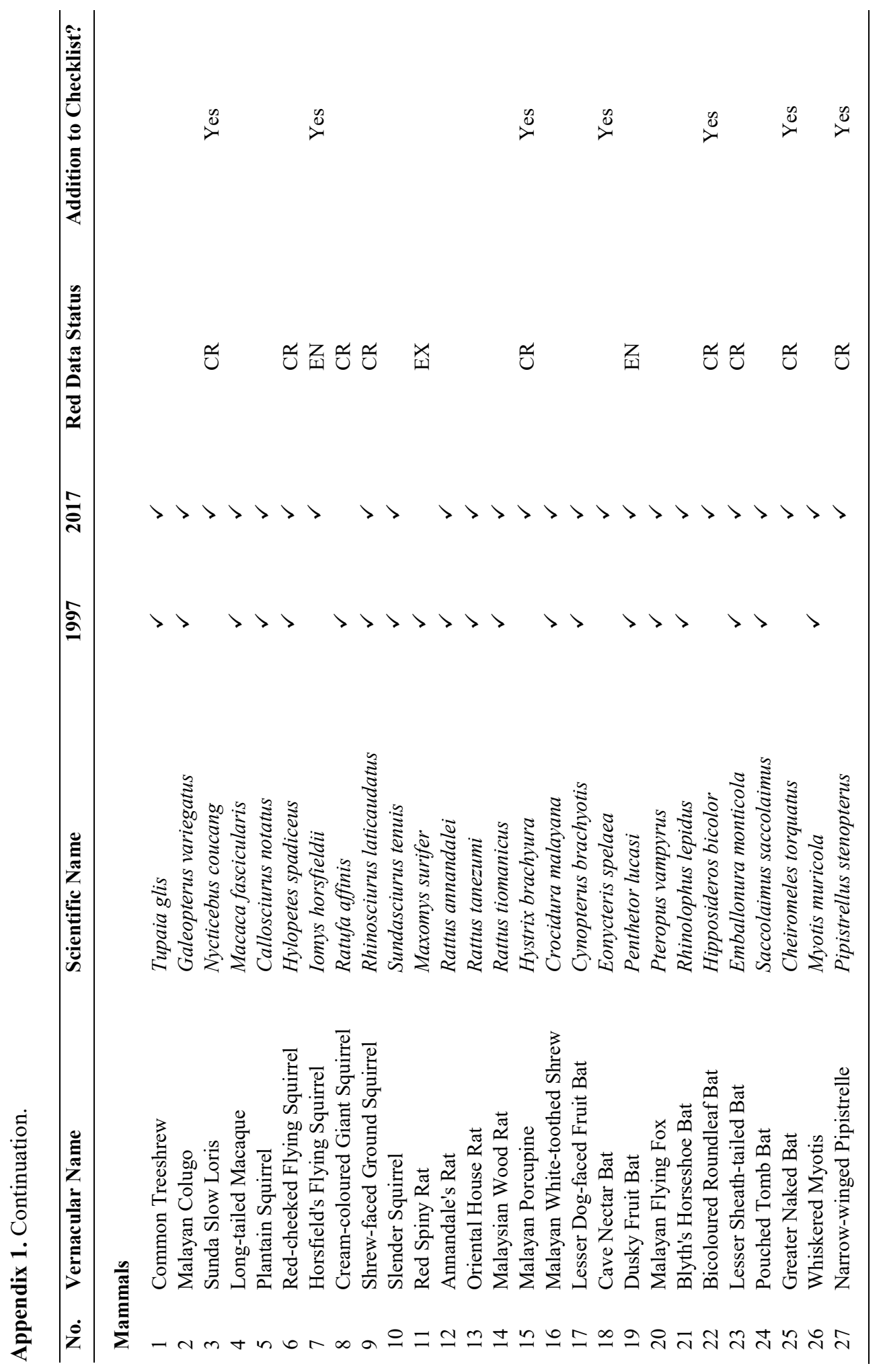




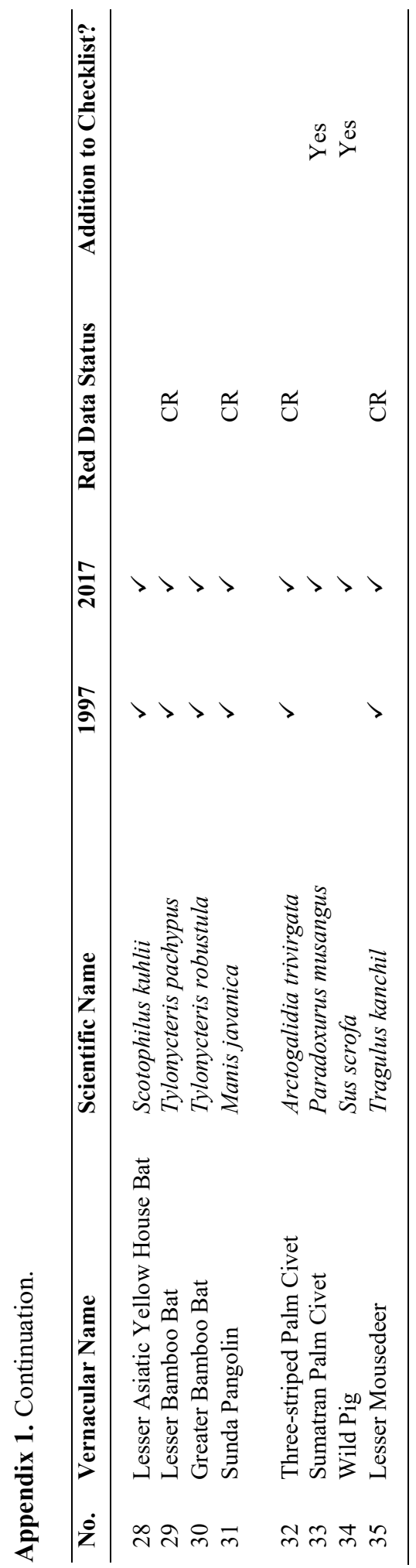

